\title{
TRANSPORTE COLETIVO: DOS FATORES IMPREVISÍVEIS E SEUS REFLEXOS NA COMPOSIÇÃO DO VALOR TARIFÁRIO
}

\author{
Juan Fernando Durán Alba ${ }^{1}$ \\ Celso Hiroshi Iocohama ${ }^{2}$ \\ Horácio Monteschio ${ }^{3}$ \\ Gustavo Kfouri ${ }^{4}$
}

Resumo: O serviço público delegado de transporte coletivo de passageiros vem padecendo em face de iniciativas que acabam por provocar desequilíbrios nas tarifas cobradas dos usuários. Destarte, se destacam os relacionados às iniciativas legislativas criadoras de isenções; a autorização, pelo Poder Público, de práticas de transportes alternativos; a ocorrência de transportes alternativos não autorizados; bem como a interferência política no valor da tarifa pelo poder concedente. Dentro desse cenário é imprescindível a criação de um marco legal com regras mais adaptáveis e peculiares à sua realidade operacional, sobretudo a fim de se evitar a superposição excessiva de entes fiscalizatórios e regulatórios.

Palavras chave: Organização Administrativa; Contratação Pública; Serviços Públicos; Transporte público e Fiscalização do Concessionário.

\footnotetext{
${ }^{1}$ Professor Titular de Direito Constitucional da Faculdad de Derecho/ Universidad de Valladolid. Licenciado y doctor en Derecho por la Universidad de Valladolid. Profesor Titular de Derecho Constitucional en la Facultad de Derecho de Valladolid. Abogado. Subdirector de la Revista General de Derecho Constitucional, editada por IustelPortal de Derecho, y miembro de su Consejo Editorial (desde 2016). Secretario de la Facultad de Derecho de Valladolid (2004-2008). Letrado de adscripción temporal en el Tribunal Constitucional (2008-2014). Vocal de la Junta Electoral de Castilla y León (2007-2008).

${ }^{2}$ Possui graduação em Direito pela Faculdade de Direito de Umuarama (1989), mestrado em Direito das Relações Sociais pela Universidade Estadual de Londrina (1996), doutorado em Direito pela Pontifícia Universidade Católica de São Paulo (2001), especialização em Docência do Ensino Superior pela Universidade Paranaense (2003) e doutorado em Educação pela Universidade de São Paulo (2011). Atualmente é professor titular de Direito Processual Civil I, da Universidade Paranaense, Campus Sede. Coordenador do Programa de Mestrado em Direito Processual e Cidadania da Unipar (desde 2008). É vice-presidente do Comitê de Ética em Pesquisa envolvendo Seres Humanos da UNIPAR.

${ }^{3}$ Doutor em Direito pela FADISP. Mestre em Direitos da Personalidade pela UNICESUMAR. Com Estágio em andamento de Pós-doutorado pelo UNICURITIBA. Com Estágio em andamento de Pós-doutorado em Direitos Humanos pelo Ius Gentium Conimbrigae da Faculdade de Direito da Universidade de Coimbra-Portugal. Professor de Direito Administrativo e Processo Administrativo do UNICURITIBA.

${ }^{4}$ Investigador, membro dos grupos de pesquisa Cidadania Empresarial no Século XXI - UNICURITIBA Brasil, e integrante do grupo de Pesquisa Internacional - REDTH (Rede de Estudos em Direitos Humanos e Transnacionalidade)
} 


\section{INTRODUÇÃO}

Há uma questão muito antiga e crônica nos serviços públicos: o embate entre os aspectos puramente técnicos e os aspectos e interesses políticos. Os primeiros são representados pelos técnicos do serviço público e os segundos pelos gestores eleitos.

No Brasil, alguns governos, imbuídos de iniciativas demagógicas tentam impor às empresas que prestam serviços públicos, unilateral e coercitivamente, a redução de tarifas sob a alegação apenas retórica de que ela seria elevada. Trata-se de uma espécie de "força centrípeta" cujo vetor parte de fora para dentro. De outra banda, há uma "força centrífuga" reclamada pelo concessionário - que pressiona à expansão tarifária. Nesse sentido, não concedem reajustes nem revisões - o que impõe a judicialização do tema. Por sua vez, as tentativas de redução unilateral da tarifa com fundamentos meramente retóricos e sem a devida justificativa técnico-econômica, têm sido corrigidas e anuladas pelo Poder Judiciário. ${ }^{4}$

Um elemento que faz parte desse universo de ordem política é a formação de um certo acordo branco e secreto que há entre essas as empresas de transporte e a classe política. Empresas temerosas de verem seus contratos ameaçados e agentes do governo temendo críticas impopulares aliam-se em pactos imorais de custeio (doações formais e informais) para campanhas políticas e postergações combinadas de reajustes tarifários que seriam impopulares em certos momentos para, em troca, praticar tarifas nem sempre reais.

Outro estratagema relativamente comum é a prática de uma espécie de lock-out $t^{5}$ na prestação serviço a fim de pressionar reajustes ou revisões tarifários. Como o princípio da continuidade $^{6}$ do serviço público impede a sua paralização, há a criação artificial de um caso fortuito que se concretiza através de uma greve combinada e com reivindicações excessivas. A

\footnotetext{
${ }^{4}$ CARVAlHO FILHO, José dos Santos. Manual de Direito Administrativo. Atlas, 28 a Edição, 2014, p. 406

${ }^{5}$ Lock-out ou Locaute. O lockout é o fechamento da empresa num conflito patrão - empregado por iniciativa daquele. É um fechamento patronal, na tradução aproximada do termo inglês. Muito embora seja considerada a greve um direito do trabalhador, evoluiu o pensamento moderno no sentido de tornar o lockout do empregador uma agressão à sociedade e, portanto, ilegítimo o seu exercício. Sofreu, portanto, um retrocesso em comparação ao direito de greve. A Lei $\mathrm{n}^{\mathbf{0}} \mathbf{7 . 7 8 3 / 1 9 8 9}$ proíbe o locaute garantindo aos obreiros todos os direitos trabalhistas durante o período de paralisação do trabalho, considerando o período de locaute como de interrupção do liame empregatício. "O simples fato de garantir o abastecimento, mas sem atender aos pressupostos legais para a deflagração de greve não torna o movimento legal. Quando se trata de autônomo rodoviário, caracteriza-se como no caso lock-out". O TST, como evidenciado, tratou de não dar legitimidade à manobra dos rodoviários. Brasil. Tribunal Superior do Trabalho, RODC 27434 / 1991, DJ 2205 1992, p. 7269, Relator Ministro Marcelo Pimentel. ${ }^{6} \mathrm{O}$ princípio da continuidade, também chamado de Princípio da Permanência, consiste na proibição da interrupção total do desempenho de atividades do serviço público prestadas a população e seus usuários. Diante disso, entende-se que o serviço público, como atividade de interesse coletivo, visando a sua aplicação diretamente a população, não pode parar, deve ele ser sempre continuo, pois sua paralisação total, ou até mesmo parcial, poderá acarretar prejuízos aos seus usuários. DI PIETRO, Maria Sylvia Zanella. Direito Administrativo, $27^{\mathrm{a}}$ ed., São Paulo: Atlas, 2014, p. 112-113.
} 
empresa - pela falta dos motoristas e cobradores - cessa o serviço e faz uma pressão sobre o poder público e sobre a população. Nesse azáfama de confusão, a empresa obtém ganhos tarifários, que não obteria em condições normais, mas que estavam escondidos em meio das reivindicações de ordem laboral.

O presente trabalho busca discutir aspectos relacionado a tema tão recorrente no cotidiano da gestão pública, com o intuito de se criar uma certeza na fixação do contrato administrativo, assegurando garantias mínimas as partes signatárias, aptas a garantir o direito do concedente e do cessionário.

\section{AS ISENÇÕES TARIFÁRIAS: UMA PRESSÃO CONSTANTE FORMULADA PELA CLASSE POLÍTICA}

Um dos fatores de constante pressão no preço das tarifas é o ímpeto de legislar criando isenções e gratuidades para certos tipos de usuários (idosos, estudantes, deficientes, desempregados, doentes, etc.) ${ }^{7}$. Qualquer isenção gerará desequilíbrio remuneratório. O espírito mais emotivo ${ }^{8}$ do que racional do brasileiro, não consegue perceber que há uma equação matemática inexorável ao proporcionar esse benefício. Basta se manter a coerência logica para concluir que, a cada nova isenção concedida sem a respectiva indicação da fonte de seu custeio ${ }^{9}$, haverá um aumento do valor da tarifa para aquele usuário que não pertence ao grupo isento, ou seja, ao grupo denominado de "passageiros pagantes”. Um exemplo é a isenção para o idoso.

A Constituição Federal assegurou aos maiores de 65 anos a gratuidade nos transportes coletivos urbanos e metropolitanos no $\S 2^{\circ}$ do art. 230 e pelo Estatuto do Idoso, Lei $n^{\circ}$ 10.741/2003, que em seu art. 39, caput, reproduziu a mesma garantia. Sendo o comando constitucional de eficácia plena sua aplicação e imediata e a lei do idoso apenas o confirmou ${ }^{10}$.

\footnotetext{
${ }^{7}$ A Lei de Concessões prevê em seu art. 35 que: A estipulação de novos benefícios tarifários pelo poder concedente, fica condicionada à previsão, em lei, da origem dos recursos ou da simultânea revisão da estrutura tarifária do concessionário ou permissionário, de forma a preservar o equilíbrio econômico-financeiro do contrato. ${ }^{8}$ Acerca do espírito emotivo do brasileiro, é interessante examinar o capítulo III - "Da sociedade erótica" - da obra do embaixador José Osvaldo de Meira Penna, Em Berço Esplêndido - ensaios de psicologia coletiva brasileira Ed. Topbooks, $2^{\mathrm{a}}$ ed., Rio de Janeiro, 2000, p. 161-304.

${ }^{9}$ Trata-se de uma imposição constitucional explícita (CF, art. 37, XXI) vinculada a outros dispositivos constitucionais: supremacia do interesse público, isonomia, razoabilidade, proporcionalidade, moralidade. Há também outros dispositivos infraconstitucionais: Lei 8.666/93, artigos 40, XI, XIV, "c"; art. 58, I e $\S \S 1^{\circ}$ e $2^{\circ}$; art. 65, II, "d", §5 . Também a própria Lei 8.987/97em seu art. $9^{\circ}$, §§ $3^{\circ}$ e $4^{\circ}$.

${ }^{10}$ Dentro do mesmo aspecto social, a Lei n. 8.999, de 29.6.1994, concedeu passe livre às pessoas portadoras de deficiência, comprovadamente carentes, no sistema de transporte coletivo interestadual. Isso com fundamento no princípio da solidariedade, previsto no art. $3^{\circ} \mathrm{da} \mathrm{CF}$.
} 
Apesar de esse tipo de iniciativa ser própria do Poder Executivo ${ }^{11}$, são muito comuns as absurdas propostas de isenções feitas por Deputados Estaduais e Vereadores pouco instruídos no assunto. Essas iniciativas se constituem em pressão permanente e latente no sistema tarifário.

No mesmo sentido se encontra a chamada gratuidade do passe livre estudantil. Fruto de um casuísmo emocional nascido nas manifestações de 2013, em 2014 um deputado do PSB de Sergipe apresentou um projeto de lei que institui o passe livre estudantil, como garantia do direito social ao transporte, para alunos matriculados em instituições públicas ou privadas de ensino. O projeto de lei define passe livre estudantil como a gratuidade do transporte rodoviário dos alunos beneficiários, no âmbito dos serviços públicos de transporte coletivo, prestados direta ou indiretamente pela União, pelos Estados, Distrito Federal ou Municípios.

Entre outros ônus causados, ao concessionário dos serviços de transporte, devem ser acrescidos os decorrentes da estrutura administrativa a ser criada para sua implementação e manutenção, aliado ao fato de que atinge um contrato administrativo em plena vigência, portanto tornando ainda mais complexa a contabilização do contingente de estudantes isentos. Como decorrência, seriam evidentes fatores de impacto no equilíbrio.

Outro segmento social que impacta as concessões de serviços de transporte coletivo é a dos portadores de necessidades especiais. Com a entrada em vigor Lei $\mathrm{n}^{\circ}$ 8.899/94, posteriormente regulada pelo Decreto Federal 3.961 de 2000, a qual concede passe livre às pessoas portadoras de deficiência no sistema de transporte coletivo interestadual, trouxe forte impacto nas relações entre poder concedente e concessionário do serviço público de transporte coletivo.

No que concerne ao sistema de passe livre para o deficiente emite cerca de 8 mil credenciais por mês. São analisados, aproximadamente 145 mil processos por ano. Hoje, o programa conta com 200 mil pessoas, com potencial para atender a um público de quase 2,5 milhões de pessoas, segundo estimativas do cadastro de Benefício de Prestação Continuada do Ministério da Previdência Social ${ }^{12}$.

$\mathrm{Na}$ mesma esteira de concessões feitas pelo legislador pátrio, cabe ainda citar a formulada em favor dos desempregados. ${ }^{13}$

\footnotetext{
${ }^{11}$ Pois o contido no art. $61, \S 1^{\circ}$, alínea "b" da Constituição Federal define que são de iniciativa privativa do Chefe do Poder Executivo, as leis que versam sobre "organização administrativa e judiciária, matéria tributária e orçamentária, serviços públicos e pessoal da administração dos territórios".

12 Disponível em: http://www.transportes.gov.br/ultimas-noticias/6796-usu\%C3\%A1rios-e-interessados-podemrenovar-ou-se-inscrever-no-passe-livre-sem-sair-de-casa.html

${ }^{13} \mathrm{O}$ metrô de São Paulo instituiu a uma credencial para o trabalhador desempregado tem validade por 90 dias e é fornecida apenas em caso de demissão sem justa causa para quem está desempregado por um período mínimo de um mês e máximo de seis meses. O usuário deve ter trabalhado pelo menos 6 meses no último emprego com registro em carteira. Trata-se de uma medida ainda restrita a esse serviço mas que repercute na criatividade
} 
São pressões que, em geral, não levam conta a existência de custos como combustível, manutenção dos veículos, renovação e modernização da frota e remuneração dos funcionários. É muito difícil encontrar países desenvolvidos que disponibilizem passe livre irrestrito em meios de transporte coletivo. Pautas de uma minoria não deveriam ser adotadas em detrimento da maioria ${ }^{14}$.

\subsection{AS IMPREVISÕES DE ORDEM LOGÍSTICA, DE ORDEM ECONÔMICA,} ADMINISTRATIVA E AMBIENTAL

Diferentemente de outras concessões - como por exemplo, o pedágio, distribuição de energia elétrica, saneamento - o transporte coletivo vive em um ambiente constante de intervenções horizontais. Essas intervenções também podem ser denominadas de externalidades $^{15}$. No presente caso, se tratam de externalidades negativas. Fenômenos externos que não beneficiam exatamente esse serviço público, ao contrário, prejudicam sua saúde, seu êxito.

A primeira das externalidades apontadas é a do serviço eventual autorizado. Trata-se de uma intervenção externa com serviços particulares análogos e alternativos que exercem uma pressão constante de serviços. A autorização dada para a operação de vans, fretamentos eventuais e linhas intermunicipais de transporte de doentes vêm exercendo cada vez mais pressão na equação econômica do contrato, fazendo constante pressão na tarifa dada a diminuição cada vez maior do fluxo de passageiros ${ }^{16}$. Essa modalidade, conforme a própria norma Decreto Federal n n $^{\mathrm{2}} .521 / 98$ a denomina como "complementar" ao sistema de transporte

\footnotetext{
legislativa das várias casas parlamentares do Brasil. Disponível em: http://www.cidadao.sp.gov.br/servico.php?serv=303786.

${ }^{14} \mathrm{http}$ //questaodeperspectiva.com.br/2016/01/24/queremos-transporte-gratuito-ou-de-qualidade/.

${ }^{15}$ ECONOMIAS EXTERNAS (Externalidades). Benefícios obtidos por empresas que se formam (ou já existentes) em decorrência da implantação de um serviço público (por exemplo, energia elétrica) ou de uma indústria, proporcionando à primeira vantagens antes inexistentes. Por exemplo, a construção de uma rodovia pode permitir aos produtores agrícolas próximos custos de transporte mais baixos e acesso mais rápido aos mercados consumidores. A existência de economias externas permite em geral uma redução de custos para as empresas e significa uma importante alavanca do desenvolvimento econômico. Muitas empresas, antes de tomar a decisão de se instalar em determinados locais, avaliam seu potencial presente e futuro de economias externas. O contrário acontece quando a instalação de certas atividades traz aumentos de custos para as empresas ou afugenta clientes ou, ainda, desestimula a demanda de certos produtos. Nesse caso, ocorrem as "deseconomias externas", como, por exemplo, quando indústrias contaminam com chumbo as pastagens e águas adjacentes: o leite produzido na região pode ter sua demanda em queda não apenas por constatar-se que o produto contém aquele metal, como pelo simples fato de que os consumidores, sabendo da origem do leite, se recusam a comprá-lo, por precaução. SANDRONI, Paulo Novíssimo dicionário de economia. 5. ed. São Paulo: Best Seller, 2000, p. 193.

${ }^{16}$ O IPEA, no ano de 2004, fez um importante estudo sobre esse fenômeno. V. IPEA. Regulação e organização do transporte público urbano em cidades brasileiras: estudo de caso. Ministério das Cidades, Brasília, 2004, p. 15.
} 
coletivo essencial. Por isso há a importância de haver regras claras a seu respeito a fim de não ferir direitos já assegurados ao transporte regular.

No mesmo pensar há os clandestinos - conhecidos popularmente como "ônibus piratas". ${ }^{17}$ Esses serviços de transportes operam sem qualquer autorização. Muito embora essas atividades sejam passíveis de multa e até mesmo de apreensão dos veículos, considerável é o número de aventureiros que se arriscam nessa atividade ao arrepio da Lei. A falta de fiscalização suficiente e um poder administrativo de polícia precário por parte do poder público acabam por criar um ambiente favorável a esse tipo de prática.

O transporte clandestino coloca em risco a vida dos passageiros devido ao estado em geral precário dos veículos e à falta de compromisso dos infratores com questões regulamentadas, tais como inspeção veicular prévia, antecedência criminal dos motoristas, itens e equipamentos obrigatórios (pneus, extintor de incêndio, cinto de segurança) e, principalmente, a não observância aos direitos dos usuários; falta de seguros e dos requisitos ambientais de não poluição. Entre os vários impactos já citados, há também a afetação direta à geração de empregos formais no sistema de transporte público, bem como a retirada de recursos que seriam destinados à melhoria da infraestrutura do sistema regular de transporte ${ }^{18}$.

Cabe ressaltar que esse transporte não possui qualquer compromisso para com a sociedade. Ao contrário, visa apenas ganhos monetários a qualquer custo ${ }^{19}$.

Outra externalidade inevitável - que não pode ser taxada de "clandestina" - é o surgimento de aplicativos eletrônicos fruto de novas tecnologias que até há pouco tempo não eram cogitadas. Tratam-se de sistemas alternativos eletrônicos privados como o UBER ${ }^{20}$,

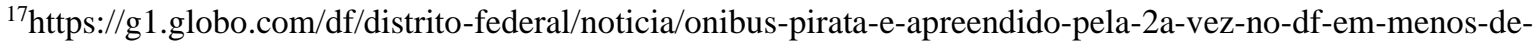
um-mes.ghtml

${ }^{18} \mathrm{http}: / /$ abar.org.br/transporte-clandestino-de-passageiros-e-crime/

${ }^{19}$ Desde março de 2014, entraram em vigor as novas medidas instituídas pela Resolução $\mathrm{n}^{\circ}$ 4.287/2014, que prevê a apreensão, por no mínimo 72 horas, do veículo flagrado na prática do transporte clandestino. Mas trata-se de uma iniciativa federal. Nos Estados, o problema persiste de maneira bastante crítica.

${ }^{20}$ Uber é um serviço de carona remunerada. O termo do usuário do aplicativo menciona que a empresa oferece informações e os meios para obter serviços de transporte oferecidos por prestadores de transporte terceirizados, condutores e operadores de veículos que podem ser solicitados através do uso de um aplicativo fornecido pelo Uber e baixado e instalado em dispositivos móveis pessoais. Hoje ele é regulamentado pela Lei $\mathrm{n}^{\circ}$ 13.640/2018, que altero a Lei $\mathrm{n}^{\circ}$ 12.578/2012, com o objetivo de regulamentar o transporte remunerado privado individual de passageiros.
} 
BUSER $^{21}$ e o BlaBlaCar ${ }^{22}$ vêm sendo questionados pelos setores como o de taxi e até mesmo pelos de fretamentos autorizados de vans e ônibus - especialmente o BlaBlaCar que compartilha caronas em viagens intermunicipais e interestaduais.

Inicialmente deve-se dizer que essas empresas ou plataformas virtuais prestam um serviço que é considerado um serviço de transporte privado. Também pode-se observar que tal definição não estava orginalmente contemplada no rol de serviços de transportes previstos na Lei 12.587/2012, que trata da Política Nacional de Mobilidade Urbana. Tudo começou como a UBER.

Esses serviços, muito embora sejam de caráter privado e não demonstrem elementos essenciais para adequação à natureza jurídica de serviço público, possui alguns elementos que o caracterizam como serviço de utilidade pública. A inexorável intervenção estatal nessa atividade se deu em razão da necessidade do ordenamento jurídico, e não por incapacidade do particular em executar o serviço ou pela essencialidade da própria atividade. Trata-se, portanto, de um serviço com relevo social, desprovido, contudo, de essencialidade. Caso ocorra sua paralisação, o impacto nos sistemas de transporte é mínimo e não traz transtornos para a sociedade. Tem uma natureza suplementar dentre os serviços de transporte direcionado ao público e sua prestação não constitui dever imprescindível do Estado. Tudo isso é verdade.

Levando-se em tais aspectos, ressalta-se outra premissa importante, qual seja, a de que a ausência de determinada atividade econômica em sentido estrito não culmina na vedação ao seu exercício, mas sim na possibilidade de atuação do particular. É o que se extrai do princípio da livre iniciativa ${ }^{23}$, que assegura a qualquer pessoa o exercício de qualquer atividade econômica, independentemente de autorização dos órgãos públicos, salvo se previsto em lei.

De outra banda, o princípio da legalidade traz uma significativa diferença no tocante à vinculação das normas jurídicas para o Estado e para os particulares, inclusive no âmbito da

\footnotetext{
${ }^{21}$ Buser é uma empresa de tecnologia cujos SERVIÇOS, prestados através de aplicativos para dispositivos móveis e sites de internet: a) conectam uma pessoa que deseja viajar a outras pessoas que desejam fazer o mesmo trajeto, na mesma data, permitindo a formação de grupos com interesses comuns; b) conectam esses grupos com empresas cadastradas em sua plataforma que prestam serviços de transporte privado coletivo de passageiros na modalidade de frete eventual, permitindo que grupo e empresa de transporte negociem e contratem entre si serviços de transporte, do qual a BUSER não participa. A BUSER não é uma empresa de transporte, não possui frota própria de veículos e tampouco é fornecedora de bens ou serviços no setor de transportes. In https://www.buser.com.br/termos. Consultado em 09/02/2019.

${ }^{22}$ BlaBlaCar é a plataforma de caronas líder na Europa: conectamos pessoas que precisam viajar com condutores que possuem lugares disponíveis em seus carros. Com mais de 20 milhões de membros em todo o mundo e mais de 2 milhões de pessoas compartilham caronas com a BlaBlaCar todos os meses através de um website e um aplicativo móvel. Compartilha viagens de longa distância e promete certa economia de dinheiro com viagens. In https://www.blablacar.com.br/faq/pergunta/o-que-e-a-blablacar, consultado em 22/01/2019.

${ }^{23} \mathrm{O}$ princípio em questão impulsiona, no âmbito da atividade econômica, a norma geral que deve vigorar nas sociedades democráticas, baseada na liberdade e que parte da afirmação de que aos particulares é lícito fazer tudo que não seja proibido em lei.
} 
atividade econômica. Ao Estado só cabe fazer o que a lei imponha ou autorize, enquanto aos particulares é permitida a atuação com liberdade, ou seja, sempre que inexista vedação ou imposição legal de determinada conduta, esta poderá ser praticada. Diz-se então que aquele se encontra positivamente vinculado à ordem jurídica e este, por sua vez, negativamente vinculado à ordem jurídica.

Essa diferença se dá em virtude da concepção de Estado de Direito que garante que os direitos fundamentais devem ser preservados, impondo, desta forma, um limite à atuação do Estado e garantindo uma maior liberdade aos particulares.

Tal liberdade ganha contornos ainda mais marcantes quando relacionados à inovação. Como se sabe, essas plataformas tecnológicas conectam diretamente demanda e oferta no âmbito digital. Nesse seguimento, a Lei $\mathrm{n}^{\circ}$ 12.965/14, que trata do Marco Civil da Internet, trouxe alguns aspectos que são importantes demonstrar neste trabalho. Já em seu art. $2^{\circ}$, inciso $\mathrm{V}$, a referida norma previu a livre iniciativa e a livre concorrência.

Como princípio, a lei trouxe em seu artigo $3^{\circ}$, inciso VIII, a liberdade de modelos de negócios promovidos na internet. E, por fim, como objetivo, em seu artigo $4^{\circ}$, inciso III, o diploma normativo trouxe a promoção da inovação e do fomento à ampla difusão de novas tecnologias e novos modelos de acesso. Desta feita, vem se tornando impossível condicionar a possibilidade de um particular criar um modelo de negócio com a existência de regulamentação prévia estatal da sua atividade. Foi nesse espírito que a UBER, BUSER, BlaBlaCar surgiram como meios externos e alternativos ao serviço de transporte coletivo público. $\mathrm{O}$ atual quadro brasileiro nesta seara apresenta um choque de entendimentos que vem sendo judicializado com um final incerto ${ }^{24}$.

Esses serviços, sem dúvida alguma, geram um considerável reflexo no faturamento das empresas que operam linhas regulares de transporte. Há uma crítica lacuna jurídico-

\footnotetext{
${ }^{24}$ Para que não tenha problemas com a legislação referente ao transporte rodoviário, a startup tem se cercado de todo o embasamento jurídico para o trabalho. Abritta garante que todas as regras definidas no Decreto $\mathrm{n}^{\circ}$ 44.035/2005, que regulamenta o transporte fretado de passageiros em Minas Gerais, estão sendo respeitadas. As empresas parceiras que farão as viagens são licenciadas pela Agência Nacional de Transportes Terrestres (ANTT) e pelo Departamento de Edificações e Estradas de Rodagem do Estado de Minas Gerais (DEER). O empresário conta que uma iniciativa parecida foi feita na Alemanha e atinge boa parte do mercado desse país. Ele espera ainda que haja uma mudança na legislação brasileira sobre transporte rodoviário, assim como aconteceu com o serviço de táxi, depois que o Uber entrou no mercado brasileiro. "A lei é ultrapassada. Entendemos que no passado ela era importante para um controle, mas hoje com a tecnologia é mais fácil ter uma viagem com conforto e segurança". O DEER/MG informou que "o transporte remunerado de pessoas tem que estar de acordo com o estabelecido no Decreto $n^{\circ} 44.035 / 2005$, que disciplina a autorização para a prestação de serviço fretado de transporte rodoviário intermunicipal, e caso isto não ocorra, a empresa será punida de acordo com a legislação". Afirmam que o Buser, na prática, está anunciando a criação de verdadeiras linhas de transporte público intermunicipal. Ocorre que essa atividade é privativa do Estado. A prestação por terceiros depende de prévia licitação. Disponível em: https://www.hojeemdia.com.br/primeiro-plano/uber-do-\%C3\%B4nibus-buser-estreiacomo-alternativa-para-transporte-e-quer-parceria-com-concorrentes-1.537136. Acessado em 07.02.1019.
} 
regulatória no Brasil nesse sentido. Os editais não preveem essa externalidade - que é um risco mercadológico - e o Poder Público não quer ser aliado incondicional de nenhum interesse, uma vez que o usuário parece não se opor aos serviços oferecidos por essas plataformas.

Problemas relativos à falta de planejamento urbano também contribuem para a fragilidade econômica do sistema. Trata-se de outra externalidade negativa. $\mathrm{O}$ acúmulo de veículos nas ruas causa prejuízos, estresse, acidentes e poluição e tende a ficar pior nos próximos anos. O problema agravou-se nas últimas décadas por conta da concentração de pessoas nas cidades; da falta de planejamento urbano; dos fortes incentivos à indústria automotora e ao maior poder de consumo das famílias. Isso tudo provocou o que os especialistas chamam de crise de mobilidade urbana. Segundo o relatório "Estado das Cidades da América Latina e Caribe", $80 \%$ da população latino-americana vive em centros urbanos e 14\% (cerca de 65 milhões) habita metrópoles ${ }^{25}$. Ocorre que esse aumento contínuo da população urbana não foi acompanhado de políticas de urbanização e infraestrutura. A má qualidade do transporte público e o incentivo ao consumo tem feiro a população optar pelo transporte individual. O crescimento do transporte individual, por sua vez, desestimula investimentos no coletivo. É, sem dúvida um círculo vicioso.

Segundo o Observatório das Metrópoles, a frota de veículos nas metrópoles brasileiras dobrou nos últimos dez anos, com um crescimento médio de $77 \%{ }^{26}$. Os ônibus parados no trânsito gastam mais combustível e fazem percursos mais demorados. As empresas são obrigadas, então, a gastar mais com o serviço, colocando mais veículos nas ruas e repassando o custo para a tarifa. Além disso, há uma piora da qualidade da saúde dos moradores, uma vez que a fumaça dos veículos é considerada a maior causadora da poluição atmosférica.

Por conta da demora no trânsito, há um acréscimo do uso de motocicletas, que ocupam menos espaço no tráfego. Porém, elas poluem mais do que veículos novos e são as principais causadoras de mortes, gerando custos sociais elevados.

As modificações no trânsito, obras de viação intermináveis, mudanças de local de terminais, tempo cada vez maior na chegada e nas saídas das grandes cidades também afetam o consumo e o equilíbrio financeiro dos contratos.

Por sua vez, os serviços públicos de transporte estabelecidos e regulados pelo Poder Público estão submetidos à exigências cada vez mais crescentes no que concerne à prevenção de danos ambientais difusos e coletivos.

\footnotetext{
${ }^{25}$ Disponível em https://fernandonogueiracosta.files.wordpress.com/2012/08/estado-da-cidades-da-amc3a9ricalatina-e-do-caribe_2012.pdf. Consultado em 30.01.2019.

${ }^{26}$ Disponível em http://observatoriodasmetropoles.net.br/wp/. Consultado em 30.10.2019.
} 
No Brasil a partir década 80 iniciou-se um processo de mudanças, principalmente na legislação da área ambiental. Em 17/01/1981, foi sancionada a Lei $n^{\circ} 6.938$, que institui a Política Nacional do Meio Ambiente e os instrumentos para se fazer a gestão ambiental, e outras importantes como a Lei $n^{\circ}$ 9.605/98, que dispõe sobre Crimes Ambientais. Desde então, mudanças baseadas no novo conceito de gestão com base no Desenvolvimento Sustentável que incluem os conceitos da teoria da qualidade total, processo de gestão ambiental e das certificações de empresas - vêm acontecendo.

Após a instituição do Sistema Nacional de Meio Ambiente - SISNAMA, em 1986 foi publicada a Resolução ${ }^{\circ} 01$ do CONAMA - Conselho Nacional de Meio Ambiente pertencente a este sistema, instituindo a obrigatoriedade da realização de Estudos de Impactos Ambientais para qualquer empreendimento público ou privado que apresentasse impactos aos meios físico, biológico ou socioeconômico na região a ser implantado. Ocorre que os poderes públicos junto com promotorias de meio ambiente e ONG's - vêm exigindo o cumprimento de medidas ambientais cuja execução representam custos evidentes que têm apenas previsões genéricas nos editais de licitação ${ }^{27}$. Fato é que as empresas e prestadores do sistema privado (fretamentos ocasionais); as linhas da saúde; os clandestinos e os aplicativos eletrônicos não estão obrigados a aderir a esses programas e exigências ${ }^{28}$ - o que resulta em evidente concorrência desleal, uma vez que sem esses custos os concorrentes externos podem praticar preços menores, ao passo que as empresas do sistema regular arcam com esses ônus que são repassados de alguma forma nas tarifas.

\footnotetext{
${ }^{27}$ Exemplo disso são os: PROCONVE - Programa de Controle de Poluição do Ar por veículos Automotores, instituído pela resolução CONAMA n ${ }^{\circ} 18$ de 06/05/86, ou indiretamente através do estimulo do uso racional da energia como o Programa Nacional da Racionalização do Uso dos Derivados do Petróleo e do Gás Natural (CONPET), que segue as diretrizes do Programa Nacional de Racionalização da Produção e do Uso de Energia, conduzido pelo Ministério de Minas e Energia criado em 18 de julho de 1991 e por último o Projeto EconomizAR, lançado em 1996 em âmbito nacional, fruto de parcerias envolvendo a Petrobrás e as entidades filiadas à Confederação Nacional dos Transportes.

${ }^{28}$ A lista abaixo relaciona as práticas exigidas das empresas pelo PROCONVE e CONPET:

- Reciclagem ou reaproveitamento de resíduos, sucatas e lixo; - Disposição adequada dos resíduos sólidos;

- Controle das emissões atmosféricas; - Controle de ruídos e vibrações; - Redução do uso de fluidos veiculares;

- Conservação de energia;

- Conservação de água; - Controle e recuperação ou reciclagem das descargas (efluentes) líquidas;- A busca por fornecedores e parceiros com prática ambientais.- Treinamento para os colaboradores em práticas ambientais. Entretanto para cada um destes itens as empresas estão buscando soluções técnico/econômicas para a sua forma correta disposição ou tratamento.
} 


\section{A SUPERPOSIÇÃO DE ENTES: FISCALIZATÓRIOS E REGULATÓRIO}

O arranjo jurídico-institucional dos serviços públicos no Brasil é bastante intrincado. Um serviço está imerso em muitas instâncias fiscalizatórias e regulatórias funcionando sob comandos legais às vezes antinômicos.

\subsection{Poder Concedente e Agências reguladoras}

O ente fiscalizatório na concessão é, por excelência, o Poder Concedente. A Lei de Concessões em seu art. 29 aponta os encargos do poder concedente, e logo no inciso I está a obrigação de "regulamentar o serviço concedido e fiscalizar permanentemente a sua prestação". O poder concedente não se confunde com a Administração Pública. Vale ressaltar que "o poder concedente é o ente federativo titular da competência para prestar o serviço"29 Assim, se tem que o poder concedente é o Estado, pois é este quem tem o dever de prestar os serviços públicos. Assim, além de cláusula contratual determinando a fiscalização por parte do concedente, a lei obriga a sua efetiva realização, não se tratando de mera discricionariedade, mas de obrigação legal.

Destaque-se que a fiscalização apresenta contornos de dever-poder para o Estado. Não se trata de uma faculdade do poder concedente, exercitável apenas se for julgado necessário. O poder concedente não dispõe de liberdade para escolher entre fiscalizar e não fiscalizar. Está jungido ao dever de adotar providências rotineiras, permanentes e contínuas de acompanhamento da atividade do concessionário. ${ }^{30}$

O concessionário está obrigado a executar seus deveres jurídicos, nos termos do contrato e das normas técnicas previstas e tomando em vista a regulamentação produzida pelo poder concedente. Não há vínculo de subordinação hierárquica entre o poder concedente e o concessionário. Há competências estatais anômalas, em virtude das quais se reduz a autonomia do concessionário relativamente à prestação do serviço público ${ }^{31}$.

Quando a Administração, pela via legislativa, investe o poder concedente de poderes, estes devem ser utilizados tendo em vista a satisfação do interesse da coletividade, por ser "a concessão um instituto oriundo da necessidade de satisfazer pelo melhor modo possível o

\footnotetext{
${ }^{29}$ JUSTEN FILHO, op cit, p. 655

30 JUSTEN FILHO, idem p. 323

31 JUSTEN FILHO, idem, p. 657
} 
interesse público, dispõe o concedente de todos os meios necessários para adequá-la ao alcance deste propósito" ${ }^{32}$.

Assim “a zelar por interesses de terceiros, o poder concedente ressalta o aspecto funcional de sua posição jurídica. Enquanto os usuários e delegatários buscam apenas a satisfação dos seus interesses, o concedente visa proteger o interesse coletivo. ${ }^{33}$

Como já dito, os deveres-poderes são instrumentos que são utilizados para se alcançar os interesses dos administrados, aqui aparecem como obrigação, ou seja, nessa situação o poder concedente deve utilizar da fiscalização para que se possibilite uma prestação adequada dos serviços públicos delegados.

Contudo, o poder concedente deve demonstrar precisamente a necessidade de salvaguardar o interesse público, sob pena de caracterizar abuso de poder. É inconstitucional o Estado exercitar suas prerrogativas por meio da invocação do argumento isolado de superioridade do interesse público. Todos os poderes exorbitantes, reconhecidos ao Estado, são instrumentais da realização concreta do interesse público. Por isso, quando o Estado invoca tais poderes, deverá demonstrar, concretamente o interesse público que pretende realizar e a adequação do ato praticado para consecução desse objetivo ${ }^{34}$.

Nas palavras de Justen Filho "o exercício destemperado e prepotente do poder de polícia é potencialmente apto a danificar algumas liberdades e garantias fundamentais. $\mathrm{O}$ abuso de poder consiste precisamente nesse tipo de antijuridicidade" 35 .

Não obstante isso, o poder concedente terá acesso às instalações do local de onde o concessionário executa as atividades, deverá o concessionário disponibilizar os documentos referentes ao serviço prestado, e ainda, sempre enviar informações sobre as condições financeiras da empresa. Dessa maneira tem se que a fiscalização é um acessório, um instrumento que o poder concedente tem em mãos para fazer valer os interesses dos usuários, que é a prestação adequada, contínua e eficaz do serviço público. ${ }^{36}$

Além disso, quando a concessão é feita em regime de monopólio o poder concedente deve se atentar para que terceiros não estejam indevidamente prestando os serviços concedidos, o que ocasionaria em violação dos direitos do concessionário e, afetaria a remuneração percebida ${ }^{37}$. Nas palavras de Bittencourt "a Administração Pública detém o

\footnotetext{
${ }^{32}$ MELLO, Op cit, p. 675

${ }^{33}$ BITTENCOURT, Op cit, p. 59.

${ }^{34}$ JUSTEN FILHO, Op cit, p. 170.

${ }^{35}$ JUSTEN FILHO, Op cit p. 896.

36 JUSTEN FILHO, Op cit, p. 325.

37 JUSTEN FILHO, Op cit, p. 656.
} 
encargo de controle e direção permanente sobre a prestação material do serviço público, uma vez que somente a execução se transfere ao particular contratado. [...]". ${ }^{38}$

Dentre desse dever de direção e controle, encontram-se inúmeras obrigações como, por exemplo, a fiscalização ampla da prestação do serviço e o próprio poder de modificação unilateral das cláusulas regulamentares para aperfeiçoamento da atividade. ${ }^{39}$ Vê-se que o Poder Concedente é dotado de forte poder de polícia e de fortes instrumentos de fiscalização e regulação.

Além do Poder concedente, há as agências reguladoras. Em âmbito federal há a ANTT - Agência Nacional de Transportes Terrestres ${ }^{40}$ cujas atribuições para os Transportes Internacional e Interestadual de Passageiros - TRIIP, são: a) Revisão da regulamentação que trata das medidas administrativas e penalidades aplicáveis pela ANTT ao TRIIP; b) Desenvolver estudos com o propósito de alterar aspectos da legislação que dispõe sobre a aplicação de penalidades às infrações e dos procedimentos administrativos aplicáveis ao Transporte Rodoviário Interestadual e Internacional de Passageiros (TRIIP); c) Enquadramentos mais adequados à realidade da fiscalização e procedimentos de retenção, apreensão, transbordo e interdição de veículos e interdição de estabelecimentos; d) revisão das penalidades e medidas administrativas atualmente previstas na legislação vigente no âmbito do TRIIP, assim como propor regulamentação das medidas administrativas, bem como meios necessários para suas efetivas aplicações ${ }^{41}$. Mais uma camada fiscalizatória dotada de poder de polícia e com pontenciais mudanças e reflexos permanentes nos contratos;

No Estado do Paraná, além do DER/PR - que é o Poder Concedente dotado de todos os poderes que lhe são inerentes - há ainda a AGEPAR - A Agência Reguladora de Serviços Públicos Delegados de Infraestrutura do Paraná. Foi criada pela Lei Estadual Complementar $n^{\circ}$ 94, de 23 de julho de 2002, e implantada em 21 de novembro de 2012, com a incumbência de exercer a regulação e fiscalização dos contratos das rodovias do Anel de Integração do Paraná, concedidas à iniciativa privada, além de regular o transporte rodoviário coletivo intermunicipal

\footnotetext{
${ }^{38}$ BITTENCOURT, Op cit, p. 79

${ }^{39}$ BITTENCOURT, Idem.

${ }^{40}$ BRASIL. Decreto n ${ }^{\circ} 4.130$, de 13 de fevereiro de 2002. Aprova o Regulamento e o Quadro Demonstrativo dos Cargos Comissionados e dos Cargos Comissionados Técnicos da Agência Nacional de Transportes Terrestres ANTT, e dá outras providências. A ANTT foi criada durante o governo do então Presidente Fernando Henrique Cardoso, por meio da mencionada Lei ${ }^{[4]}$, que dispõe sobre a reestruturação dos transportes aquaviário e terrestre, cria o Conselho Nacional de Integração de Políticas de Transporte (CONIT), a Agência Nacional de Transportes Terrestres, a Agência Nacional de Transportes Aquaviários (ANTAQ) e o Departamento Nacional de InfraEstrutura de Transportes (DNIT), e dá outras providências.

${ }^{41}$ Disponível:http://agendaregulatoria.antt.gov.br/index.php/content/view/3064/Revisao_da_regulamentacao_que _trata_das_medidas_administrativas_e_penalidades_aplicaveis_pela_ANTT_ao_TRIIP.html. Consultado em 03.02.2019.
} 
de passageiros e das travessias marítimas, fluviais e lacustres (em especial da travessia da baía de Guaratuba pelo sistema de ferry boat).

Em sua lei original está prevista ainda a regulação de ferrovias concedidas; terminais de transportes rodoviários, ferroviários, aeroviários, marítimos e fluviais; da exploração da faixa de domínio da malha viária e da inspeção de segurança veicular e de outros serviços de infraestrutura de transporte que puderem vir a ser delegados pelo Estado.

No rol de atribuições da AGEPAR estão de assegurar a prestação de serviços adequados ao pleno atendimento dos usuários, satisfazendo condições de qualidade, regularidade, continuidade, eficiência, segurança, atualidade e modicidade nas suas tarifas; proteger os usuários dos serviços concedidos contra o abuso do poder econômico, monopólio e o aumento arbitrário dos lucros; aferir a qualidade da prestação dos serviços regulados e realizar estudos para propor maior eficiência nas atividades públicas reguladas; aplicar penalidades decorrentes do descumprimento da legislação vigente ou dos contratos; promover a estabilidade nas relações entre o poder concedente, entidades reguladas e usuários; garantir ampla proteção aos usuários e soluções rápidas e consensuais de conflitos; decidir e homologar sobre os pedidos de revisão e reajuste de tarifas, buscando modicidade das tarifas e o equilíbrio econômicofinanceiro dos serviços públicos de infraestrutura delegados; assegurar aos usuários amplo acesso às informações sobre a prestação dos serviços públicos regulados e prévia divulgação de reajustes e revisões das tarifas; promover audiências públicas periódicas com o objetivo de avaliar a atuação da Agepar e a qualidade dos serviços prestados pelas entidades reguladas.

Com essa exposição, prima facie é fácil concluir uma conjuntura administrativa que se sobrepõe e ao invés

\subsection{Ministério Público e Tribunais de Contas}

Além do Poder Concedente e das Agências Reguladoras ainda há a intervenção fiscalizatória dos Ministérios Públicos - através de suas promotorias - e dos Tribunais de Contas.

Estabelece a Lei Federal Complementar nº 40 que o Ministério Público, instituição permanente e essencial à função jurisdicional do Estado, é responsável, perante o Judiciário, pela defesa da ordem jurídica e dos interesses indisponíveis da sociedade, pela fiel observância da Constituição e das leis, e será organizado, nos Estados, de acordo com as suas normas gerais. São princípios institucionais do Ministério Público a unidade, a indivisibilidade e a autonomia 
funcional e a principal de suas funções está a de "velar pela observância da Constituição e das leis, e promover-lhes a execução ${ }^{42}$;"

Com o tempo os Ministérios Estaduais e Federal passaram a ser dotados de divisões, promotorias de apoio, promotorias especializadas em meio ambiente, idosos, crianças, deficientes, etc. Por meio dessa especialização, o mesmo passou a ter uma atuação mais efetiva e positiva na defesa dos interesses difusos e coletivos. Um instrumento bastante utilizado e eficaz na ação ministerial é o denominado "Inquérito Civil" ${ }^{43}$. Através desse instrumento muito eficiente - o Ministério Público promove procedimentos administrativos inquisitivos destinados a uma preliminar coleta de elementos instrutórios, propiciando a persuasão do órgão do Ministério Público encarregado da tutela difusa ou coletiva colocada em análise, que sopesará: o ajuizamento da ação coletiva ou o arquivamento da investigação.

É bastante difícil defender uma mitigação da atividade do Ministério Público mas, às vezes, esse se sobrepõe ao Poder Concedente e à Agência Reguladora e inicia inquéritos civis nem sempre levando em conta as tecnicidades inerentes a determinado tipo de serviço. A atividade ministerial nesses casos, muitas vezes resulta não observa que em certas e pontuais medidas que abrangem as partes contratantes, as quais, ao final, acabam resultando em readequações que implicarão em revisões tarifárias. Trata-se, sem dúvida, de mais uma instância que integra as camadas fiscalizatórias do serviço.

Cabe, ainda ressaltar uma outra superposição de fiscalização dentro do contrato de prestação de serviços de transportes formulada pelos os Tribunais de Contas podem controlar as Agências Reguladoras. Como órgãos de controle externo, tanto o Tribunal de Contas da União (TCU) quanto os Tribunais de Contas dos Estados (TCE), em cumprimento à Constituição Federal e à legislação em vigor, fiscalizam tanto as atividades-meio quanto as atividades-fim das próprias agências reguladoras. Ao acompanhar as atividades-fim das agências reguladoras, o foco de controle incide, em um primeiro momento, principalmente sobre os estudos de viabilidade da concessão a entidades privadas, e, em um segundo momento, notadamente sobre o edital de licitação e a posterior execução contratual.

Nessas fases de fiscalização, um dos objetivos primordiais dos Tribunais de Contas é, em tese, impedir que qualquer impropriedade possa causar prejuízos ao erário e aos usuários

\footnotetext{
42 BRASIL. Lei Complementar $n^{\circ} 40$, de 14 de Dezembro de 1981, art. $3^{\circ}$.

43 Trata-se, o inquérito civil público, de um procedimento administrativo facultativo e investigatório, de cunho pré-processual, cuja atuação do Ministério Público é a de buscar coletar elementos para a propositura responsável de uma dada Ação Civil Pública. Esse arcabouço normativo se espraia na Constituição Federal (artigo 129, inciso III), correndo a seguir por leis federais (artigo $8^{\circ}, \S 1^{\circ}$, Lei n. 7.347/85; artigo $6^{\circ}$, Lei n. 7.853/89; artigo 25, inciso IV, Lei n. 8.625/93), até alcançar a competência concorrente dos Estados.
} 
finais. Essa fiscalização, no entanto, não é a regulação do mercado. Muito embora a fiscalização dos contratos de concessão seja de responsabilidade das agências reguladoras, ao TCU compete o papel que a Constituição lhe impõe enquanto órgão de controle externo, ou seja: identificar as falhas e as oportunidades de melhorias de procedimento; evitar que a entidade reguladora se desgarre das fronteiras impostas pela lei que lhe marcam o legítimo âmbito de atuação ao tomar decisões tecnicamente inconsistentes e questionáveis, não direcionadas ao implemento da finalidade legal, ou resultantes da "captura" do ente regulador por interesses das entidades reguladas 44 .

Os Tribunais de Contas entendem que a fiscalização do TCU incide, inclusive, sobre a administração indireta, formada pelas autarquias, fundações, empresas públicas e sociedades de economia mista. Notadamente sobre essas duas últimas. Ficou decidido pelo Supremo Tribunal Federal a sujeição delas à fiscalização do Tribunal de Contas, in verbis: As empresas públicas e as sociedades de economia mista, integrantes da administração indireta, estão sujeitas à fiscalização do Tribunal de Contas $[\ldots]^{45}$

Esse controle parlamentar, através dos TC's pode versar, de modo ilimitado, sobre toda a atividade desempenhada pela agência, podendo exigir a justificativa para as decisões de cunho regulatório, com ampla exigência de informações sobre as justificativas técnicocientíficas das opções adotadas. Ocorre que o controle externo, a cargo do Congresso Nacional e Assembleias Legislativas, é exercido com auxílio do Tribunal de Contas, conforme dispõe o texto constitucional em seu art. 71, razão pela qual pode o Tribunal de Contas da União a fiscalizar as atividades-fim dos órgãos reguladores. Ademais, entende-se que nenhuma lei poderá limitar essa competência do Tribunal, uma vez que ela se origina da própria Constituição Federal $^{46}$.

Em suma, a defesa que se faz dessa atuação dos Tribunais de Contas vem do fato de que a atividade da agência reguladora pode desvirtuar-se em consequência de problemas regulatórios e também pelo fato de que o órgão regulador não é infalível. Isso pode ensejar a ocorrência de falhas e impropriedades passíveis de causar prejuízos às partes envolvidas na

\footnotetext{
${ }^{44}$ MACIEIRA, Leonardo dos Santos. O problema da regulação e a competência fiscalizatória do Tribunal de Contas da União sobre as atvidades-fim dos órgãos reguladores. Revista do TCU, set/dez 2007, p. 76.

${ }^{45}$ MS 25092/DF, rel. Min. Carlos Velloso, DJ de 17 de maio de 2006.

46 “... de forma mediata ou imediata, os atos de regulação e de fiscalização das agências sobre os concessionários de serviços públicos se refletem sobre o erário. Ilustrando sua afirmação, Aragão cita como exemplo o caso de uma fiscalização equivocada da agência que pode levar a não aplicação de uma multa; ou a autorização indevida de um aumento de tarifa que pode levar ao desequilíbrio econômico-financeiro favorável à empresa. Por essa razão, o TCU tem competência para proceder à fiscalização dos atos de regulação das agências. Os órgãos reguladores muitas vezes atuam sobre segmentos da economia em que há o emprego de recursos públicos e a prestação de serviços públicos. Revista do TCU, set/dez 2007, p. 76-77.)
} 
regulação, notadamente ao erário e aos usuários de serviços públicos. Nesse contexto, inserese a fiscalização do Tribunais de Contas sobre as atividades-fim dos órgãos reguladores, ao buscar contribuir para o aprimoramento do ambiente regulatório. Em resumo: é o fiscal do fiscal $^{47}$.

\section{A FRAGILIDADE DAS BASES CONTRATUAIS DO SERVIÇO; INSTRUMENTOS DA OUTORGA ONEROSA E DO SUBSÍDIO E VIABILIDADE TÉCNICO- ECONÔMICA}

Aquilo que deveria ser fixo, sólido ou rígido - que seriam: a estrutura das bases do serviço, sua prestação e sua matriz tarifária - hoje se tornou volátil, líquido. A profusão de externalidades e exigências que pairam sobre a concessão desse serviço público o tornaram frágil sob o ponto de vista de sua sustentação financeira. São interferências exteriores permanentes e incessantes que deixam a fórmula tarifária inflamada, num processo crítico e crônico.

4.1 Outorga e subsídio na concessão do transporte coletivo: questões controvertidas

Há a possibilidade de a administração cobrar uma taxa de outorga dos licitantes que participarão do certame da concessão. Trata-se de um instrumento jurídico usado que a administração pública lança mão para arrecadar fundos para si. Outorgar nada mais é que conceder e quando ela é onerosa, indica que a concessão é feita em troca de um pagamento. A outorga é como se fosse um cheque pago pelo licitante, uma antecipação do valor que ele vai arrecadar no futuro e que tem como origem o capital próprio ou de terceiros. Esse pagamento antecipado tem impacto financeiro no projeto, se comparado ao modelo do vencedor pela menor tarifa. E, em momentos de crise, pode reduzir o interesse do setor privado. Além de precisar desembolsar um valor na entrada, demandando caixa ou financiamento, a outorga acaba resultando em tarifas mais altas, trazendo o risco de redução na demanda pelo serviço. $\mathrm{O}$ licitante vai compensar no valor da tarifa.

\footnotetext{
${ }^{47}$ Além das atividades dos Ministérios Públicos e dos Tribunais de Contas, há ainda uma latente e permanente atividade por parte da sociedade e dos poderes legislativo. Tratam-se das Ações Popular e Civil Pública que, em última análise, terão a presença do Ministério Público. O outro instrumento são as Comissões Parlamentares de Inquérito que poder ser perpetradas no seio das câmaras municipais, assembleias legislativas e até mesmo da câmara federal de deputados.
} 
O outorga onerosa é um evidente elemento de força que expande o valor do preço público - uma vez que o concessionário vai cobrir esse investimento na sua cobrança. Ademais, ela fere o princípio da modicidade tarifária ${ }^{48}$. Sabe-se que raramente o pagamento de outorga não destinado a reinvestimento, mas apenas para fazer caixa - o que agrava a insatisfação do usuário.

O subsídio ${ }^{49}$, por sua vez vem a se constituir em um instrumento que tem por objetivo específico equacionar a modicidade tarifária.

A tarifa paga pelo usuário do serviço prestado é a principal (e na maioria das vezes a única) fonte de receita do concessionário. É também a tarifa a forma pela qual o cidadão usufrui do serviço público, dessa forma a tarifa possui uma duplicidade de visões: de um lado o concessionário entende a tarifa como sua fonte de receita; de outra banda, o usuário vê a tarifa como a forma de utilizar o serviço público, desejando que a mesma seja a menor possível para não causar um desequilíbrio em suas finanças e para que possa usufruir do serviço de forma plena.

A modicidade tarifária - da qual já se falou - é uma das questões mais delicadas quando se trata de concessão, uma vez que ao mesmo tempo deve ser suficiente para remunerar de forma justa o concessionário e baixa o suficiente para permitir que todos tenham acesso ao serviço público que é considerado essencial para a sociedade.

É neste aspecto que se deve relembrar que o Estado tem o dever de proporcionar o acesso ao serviço público a todos os cidadãos e, para tanto, possui uma série de ferramentas e prerrogativas, dentre elas o subsídio, podendo efetivar a diminuição da tarifa paga pelo usuário, atingindo os princípios da modicidade tarifária e da igualdade dos usuários, possibilitando, ao mesmo tempo, a remuneração justa da concessão.

4.2 quanto aos subsídios ofertados pelo poder público

\footnotetext{
${ }^{48}$ Os que a defendem, afirmam que o pagamento da entrada seleciona os concorrentes e exclui os aventureiros, atraindo grupos mais estruturados financeiramente. Apenas pela menor tarifa, o certame acaba atraindo especuladores e fica difícil cumprir o contrato. Em suma: com a outorga, a tendência é atrair empresas mais sérias. ${ }^{49}$ Subsídio é um conceito econômico e pode ser utilizado para qualquer caso em que um ente (geralmente, mas não necessariamente, o Estado) paga parcialmente ou totalmente por uma utilidade a ser usufruída por um terceiro. RIBEIRO, Maurício Portugal. Artigo: Aspectos relevantes do subsídio a investimento em concessões e PPP. Site: observatório das Parcerias Público-Privadas. Disponível em: http://www.pppbrasil.com.br/portal/content/artigoaspectos-relevantes-do-subs\%C3\%ADdio-investimento-em-concess\%C3\%B5es-e-ppps
} 
É Importante destacar que existem diversas formas de subsídio, desde o subsídio cruzado $^{50}$ até o subsídio orçamentário do Estado, caracterizado pelo aporte por parte do Poder Público de forma direta. ${ }^{51}$ Com a edição da Lei da Mobilidade Urbana ${ }^{52}$ a possibilidade da implantação de subsídio direto para o transporte público ficou mais clara. Ao editar essa norma o legislador demonstrou preocupação em dar diretrizes concretas aos gestores do transporte público no sentido de indicar que a tarifa deve ser tal que permita a todos o acesso aos serviços, incluindo a contribuição de toda a sociedade no custeio do serviço público de tal forma que a tarifa empregada atenda ao preceito de modicidade.

Em um esforço de não deixar dúvidas quanto a este complexo e delicado assunto o legislador continuou a efetuar definições importantes para o tema, apresentando o conceito de déficit e superávit tarifário ${ }^{53}$. Do ponto de vista jurídico não há restrição na utilização de subsídio orçamentário, uma vez que a legislação traz em seu conteúdo, de forma expressa, a possibilidade do uso de subsídio. Percebe-se que tanto o legislador quanto a doutrina jurídica indicam que o subsídio tarifário é uma forma de atender a parcela mais carente da população e que não há nenhuma ilegalidade ou inconstitucionalidade na adoção dessa ferramenta.

Neste cenário fático Marçal Justen Filho faz importantes ponderações sobre a introdução superveniente de benefícios para usuários.

\begin{abstract}
Uma manifestação da alteração unilateral das condições originais da concessão reside na criação superveniente de benefícios para determinadas categorias de usuários. Essa solução equivale à ampliação dos encargos ou à redução de vantagens que compunham a equação econômico-financeira original. Em tais hipóteses, deverá ser promovida a alteração das condições da concessão, para promover a recomposição da equação original. [...]

Supõe-se que "benefícios tarifários" consistam em tratamento mais vantajoso para parte ou todos os usuários. Identifica-se o benefício tarifário quando a tarifa seja fixada em valor desvinculado dos custos a cuja remuneração se orienta. Assim, o montante arrecadado por meio da tarifa seria insuficiente para cobrir despesas necessárias à prestação do serviço e lucro assegurado ao concessionário. [...]
\end{abstract}

\footnotetext{
${ }^{50}$ Nesta modalidade de subvenção são implantados descontos para determinadas categorias de usuários sendo essa diferença monetária arcada pelos demais usuários, ou seja, o subsídio é internalizado no próprio sistema não existindo nenhum tipo de contribuição externa. P. Ex.: Linhas de ônibus altamente rentáveis, subsidia aquelas que são deficitárias. Trata-se de uma intrincada engenharia logístico-financeira que objetiva manter o sistema equilibrado.

${ }^{51}$ Ver LORENZETTI, Maria Sílvia Barros. Gratuidade no sistema de transporte público coletivo de passageiros, 2004, pág. 5. e MORAES, Jacqueline Vera Hassun e BRITO, Wilson Folgozi de. Subvenção às gratuidades: uma nova fonte de recursos para o transporte coletivo público de campinas, 2009, Weblioteca ANTP;

52 art. $9^{\circ}, \S 5^{\circ}$ da Lei $12.587 / 2012$

${ }^{53}$ A legislação identifica como sinônimos o déficit tarifário e o subsídio tarifário ( $\operatorname{art} .9^{\circ}, \S 3^{\circ}$ ), quando na realidade são conceitos bastante distintos, aquele relaciona-se com o fato de haver deficiência na relação entre os recursos arrecadados e os necessários para a prestação do serviço, enquanto este é conceituado como o complemento necessário para corrigir a falta de receita auferida. Tal conceito distinto é utilizado pelo próprio legislador ao listar as alternativas que o poder público pode lançar mão para corrigir o déficit tarifário, uma vez que utiliza as expressões "subsídios orçamentários” e "subsídios cruzados" $\left(\operatorname{art.} 9^{\circ}, \S 5^{\circ}\right)$.
} 
O benefício tarifário pode caracterizar-se como uma redução do valor nominal da tarifa. Mas também se pode cogitar da ausência de reajuste compatível com a elevação dos custos ocorrida em certo período de tempo. ${ }^{54}$

Quando há a opção pela implementação do subsídio tarifário deve-se sopesar a relação entre o subsídio e o serviço que será prestado. Jamais a subvenção deve ser uma forma de "sustentar" o sistema operado de forma indiscriminada. A forma mais recomendada de implementação do subsídio é atrelá-lo a parâmetros de eficiência na prestação do serviço, dessa forma previne-se a eventual "acomodação" do concessionário no sentido de não buscar melhorias na operação com o objetivo de redução de custos.

Em um trabalho publicado pela economista portuguesa Anabela Maria Bello da Silveira Baptista de Figueiredo Marcos, é possível verificar que a preocupação com esse tema possui âmbito internacional. A autora destaca algumas conclusões de estudos do Banco Mundial, realizados em 1986 que merecem atenção neste estudo.

\footnotetext{
Quando o nível dos subsídios cresceu na maior parte dos países europeus, despontou a necessidade de se medir a sua eficácia nos transportes públicos. Na sequência da prática crescente do recurso à subsidiação, numerosas críticas surgiram à medida que foram sendo observados os resultados. A desmotivação resultante da cobertura dos défices, através de subsídios, está, aliás, traduzida, de um modo muito nítido, na literatura que se tem centrado nesta temática. É assim que um relatório do Banco Mundial de 1986 refere que a principal razão para o fracasso dos subsídios reside no desincentivo para reduzir custos, o que, geralmente, conduz à ineficiência, a défices agravados e à necessidade viciosa de mais subsídios ${ }^{55}$
}

Percebe-se que juntamente com a implantação de subsídios é preciso tomar medidas que compilem o operador a continuar otimizando e melhorando a operação, não deixando que a subvenção seja uma forma de conforto. Há que se destacar que o subsídio ao sistema, independentemente dos passageiros transportados ou de outra relação com a operação em si, possui esse lado perverso, contudo quando se trata de subsídio ao passageiro tal situação é bastante diminuída, uma vez que é interesse do operador melhorar o sistema para atrair mais usuários e, consequentemente, aumentar a arrecadação.

\subsubsection{Estudo de Viabilidade Técnico Econômica e Ambiental - EVTEA}

\footnotetext{
${ }^{54}$ JUSTEN FILHO, Marçal. Op cit. p. 409.

${ }^{55}$ MARCOS, Anabela Maria Bello da Silveira Baptista de Figueiredo. As repercussões nos custos da atribuição de subsídios públicos às empresas de transporte colectivos, Urban Transport, A World Bank Policy Study, 1986, pp. IX e 22, 2002, p. 3.
} 
Instrumento importante muito usado nas concessões de pedágio, aeroportos, portos e afins, é o EVTEA - Estudo de Viabilidade Técnico Econômica e Ambiental. Trata-se de um documento preparatório ao edital de licitação que dá as diretrizes viáveis quanto às perspectivas mercadológicas; quantitativos de usuários; elasticidade da demanda pelo serviço; custos; eventuais subsídios; externalidades positivas e negativas; índices e critérios de reajustes e revisões; impedimentos e exigências de ordem ambiental; cronograma de amortização de bens. Enfim, todos os elementos necessários para se dar a devida segurança e previsibilidade para o particular que queira apresentar a proposta de prestação do serviço em regime de concessão.

O EVTEA não tem uma previsão legal muito detalhada. Os resultados advindos do EVTEA compreendem o conjunto de dados necessários à verificação da existência de viabilidade técnica, econômica e ambiental para a execução de uma obra de infraestrutura de transportes, ou serviço, ou conjunto delas, nos segmentos considerados, dentre as alternativas propostas. Materializa elementos como estudos de tráfego, capacidade de uso do serviço, seu nível de demanda, bem como estudos sócio-econômicos e ambientais necessários ${ }^{56}$.

O EVTEA protege tanto o particular quanto a administração pública na medida que as regras ficam claras desde o início da concessão. Aliás, desde o edital do certame. Ele faz com que diminua em muito as imprevisibilidades da prestação do serviço, tornando-o mais transparente e sendo importante instrumento para a futura resolução de eventuais conflitos, seja por meios administrativos ou até mesmo judiciais. Infelizmente ele ainda é pouco conhecido e praticamente não vem sendo usado nos editais de serviço de transporte coletivo.

\footnotetext{
${ }^{56}$ O DNIT-Departamento Nacional de Infraestrutura de Transportes adota os EVTEA como peça que precede as suas concessões. Aponta um documento do DNIT que: "Os estudos de Viabilidade Técnica, Econômica e Ambiental - EVTEA, para o Departamento de Infra-Estrutura de Transportes - DNIT, compreendem o conjunto de estudos necessários à verificação da existência de viabilidade técnica, econômica e ambiental para a execução de uma determinada obra de infraestrutura de transportes, ou conjunto delas, nos segmentos considerados, dentre as alternativas propostas, consubstanciado, principalmente nos estudos de tráfego, capacidade da rodovia e seu nível de serviço, aliados às pesquisas complementares e outras similares, bem como aos demais trabalhos e estudos de engenharia, sócio-econômicos e ambientais necessários. Assim, no DNIT, o estudo de Viabilidade Técnica, Econômica e Ambiental - EVTEA tem como objetivo principal a identificação da alternativa mais viável para a sociedade dentre as possíveis soluções elencadas preliminarmente para se resolver um determinado problema de infraestrutura de transportes. Os EVTEA's deverão ter abrangência suficiente para assegurar a compatibilidade com todos os investimentos previstos a serem implantados nas áreas de influência por todos os atores e agentes públicos e/ou privados que planejam ou executam obras que necessitarão de demandas nas rodovias estudadas. Integra a abrangência dos serviços dos estudos de viabilidade, o exame das soluções de intermodalidade do escoamento da produção regional, as melhorias do fluxo de produtos e de usuários nos seus deslocamentos, incluindo nessa análise o potencial turístico regional, o aspecto de integração social das soluções analisadas e os principais problemas de impacto ambiental decorrentes das alternativas previstas, destacando-se as imposições e limitações legais existentes." Disponível em: http://www.dnit.gov.br/download/planejamento-epesquisa/planejamento/estudos-de-viabilidade/lcs-097-2010-solic-public-texto-evtea-site-dnit.pdf. Consultado em 04.02.2019.
} 


\section{CONCLUSÃO}

Com o advento da Constituição Federal de 88 e sucessivas emendas e sobretudo da Lei de Concessões o serviço público brasileiro passou a ser revestido de uma estrita formalidade legal.

No que respeita ao serviço público de transporte coletivo de passageiros, quando este passou a ter um status de Direito fundamental-social, sua condição adquiriu um patamar de elevada seriedade. Exatamente por ser um serviço fundamental e público, o Estado assume a função precípua de promover a segurança e o bem-estar à sociedade, através da adequada prestação dos serviços que devem estar disponíveis à toda a sociedade.

Ocorre que esse serviço tal qual está disciplinado na Constituição e na legislação ordinária, como concessão e/ou permissão, tem se mostrado como estruturas rígidas que tem enfrentado problemas com a realidade dinâmica do funcionamento e do mercado do transporte coletivo, sobretudo no que concerne às externalidades negativas. Essa inadequação vem se refletindo nas constantes crises ocorridas na estabilização das tarifas do transporte, sobretudo por fatores imprevisíveis ou de difícil previsão que tornam a tarifa.

O Estado, na condição de Poder Concedente, por sua vez, tem o dever de utilizar as ferramentas jurídicas, econômicas e políticas necessárias para atingir os objetivos de bem-estar da sociedade e interesse público. Nesse aspecto, a fim de manter o serviço equilibrado e com uma tarifa módica, não há alternativa senão a implementação de algumas cautelas: a) a elaboração de editais precedida de um estudo técnico de viabilidade técnica econômica e ambiental; $b$ ) o aprimoramento da fiscalização às práticas clandestinas e ruinosas; $c$ ) privilegiar e incrementar a criação de corpos funcionais técnicos na administração pública a fim de evitar a politização dos reajustes tarifários; $d$ ) definir uma política clara de reajustes e revisões; $e$ ) se necessário, instituir subsídio tarifário uma vez que se trata de medida prevista na legislação, desde que não sejam vantagens ao concessionário, devendo ser mantido o equilíbrio econômico-financeiro do contrato.

Num âmbito mais elevado e deontológico é conveniente a criação de um marco legal próprio para esse modal de transporte - que poderia ser no bojo da própria Lei de Concessões - com regras mais adaptáveis à sua realidade operacional e às suas peculiaridades, sobretudo a fim de se evitar a superposição excessiva de entes fiscalizatórios e regulatórios. 


\section{REFERÊNCIAS}

CARVAlHO FILHO, José dos Santos. Manual de Direito Administrativo. Atlas, $28^{\mathrm{a}}$. Edição, 2014, p. 406.

DI PIETRO, Maria Sylvia Zanella. Direito Administrativo, $27^{\mathrm{a}}$ ed., São Paulo: Atlas, 2014, p. 112-113.

FERRO, Sandra Regina Oliveira Passos de Bragança; FERRO, Luiz Bruno Lisboa de Bragança. O sistema de transporte público e sua concretização como Política Pública: uma análise do direito do usuário do transporte público por ônibus de Aracaju - SE. Revista Juridica, [S.1.], v. 4, n. 33, p. 157-174, dez. 2013. ISSN 2316-753X. Disponível em:

$<$ http://revista.unicuritiba.edu.br/index.php/RevJur/article/view/754/579>. Acesso em: 18 abr. 2020. doi:http://dx.doi.org/10.21902/revistajur.2316-753X.v4i33.754.

MACIEIRA, Leonardo dos Santos. O problema da regulação e a competência fiscalizatória do Tribunal de Contas da União sobre as atividades-fim dos órgãos reguladores. Revista do TCU, set/dez 2007, p. 76.

MARCOS, Anabela Maria Bello da Silveira Baptista de Figueiredo. As repercussões nos custos da atribuição de subsídios públicos às empresas de transporte colectivos, Urban Transport, A World Bank Policy Study, 1986, pp. IX e 22, 2002, p. 3.

SANDRONI, Paulo Novíssimo dicionário de economia. 5. ed. São Paulo: Best Seller, 2000, p. 193. 